\title{
Deep electrical structure of the Central Volcanic Region and Taupo Volcanic Zone, New Zealand
}

\author{
Malcolm Ingham \\ School of Chemical and Physical Sciences, Victoria University of Wellington, PO Box 600, Wellington, New Zealand
}

(Received November 29, 2004; Revised April 22, 2005; Accepted April 23, 2005)

\begin{abstract}
Magnetotelluric measurements have been made along a transect crossing the Central Volcanic Region (CVR) and Taupo Volcanic Zone (TVZ) of the North Island of New Zealand. Analysis of the observed data using the phase tensor method shows that at the south-eastern end of the transect, where it crosses the TVZ, the data are largely 2-dimensional in character and respond to electrical structure which has a strike orientation of $\mathrm{N} 45^{\circ} \mathrm{E}$. There is however, evidence of some degree of 3-dimensionality in data from the central part of the TVZ. 2dimensional inversion and forward modelling of data indicate the existence of low resistivity beneath about 10 $\mathrm{km}$ depth centred below the Taupo Fault Belt. The existence of low resistivity beneath this depth is consistent with a low velocity zone identified from receiver function analysis and with measurements of the transition from brittle to ductile behaviour and the depth penetration of the convective systems associated with the geothermal fields within the TVZ. The low resistivity provides support for the existence of igneous intrusion to shallow depths beneath the TVZ. Data from the north-western end of the transect, where it crosses the western boundary of the CVR, are 2-dimensional and may respond to electrical structure associated with the Hauraki Rift, an active rift containing Tertiary sediments, which cuts the boundary of the CVR in this region.
\end{abstract}

Key words: Magnetotellurics, electrical resistivity, New Zealand.

\section{Introduction}

The Central Volcanic Region (CVR) of the North Island of New Zealand is a wedge-shaped area which extends from Mt Ruapehu in the south to the coast of the Bay of Plenty in the north (Fig. 1) and is the southern continuation of the Havre Trough. It is a region of on-going extension, volcanism and high heat flow and it has been argued (e.g. Stern, 1985, 1987; Cole, 1990) that the CVR therefore represents an active back-arc basin formed within continental lithosphere behind the Hikurangi subduction zone off the east coast of the North Island.

The presently active part of the CVR is the eastern part and is termed the Taupo Volcanic Zone (TVZ). The TVZ is defined by Wilson et al. (1995) as the area in which there has been active rhyolitic volcanism within the last $1.6 \mathrm{My}$. Present day andesitic volcanism, however, dominates at the southern and northern ends of the TVZ, and the eastern margin of the TVZ/CVR coincides with a lineation of andesitic volcanoes stretching from Mt. Ruapehu in the south to White Island in the Bay of Plenty. Associated with its volcanism, the TVZ contains numerous high temperature geothermal fields. These have an overall natural heat output that has been estimated as 4000-5000 MW (Bibby et al., 1995) and is far in excess of the heat output generally associated with volcanism (Hochstein et al., 1993).

The geology of the TVZ is dominated by volcaniclastics resulting from the rhyolitic and andesitic volcanism. To

Copy right(C) The Society of Geomagnetism and Earth, Planetary and Space Sciences (SGEPSS); The Seismological Society of Japan; The Volcanological Society of Japan; The Geodetic Society of Japan; The Japanese Society for Planetary Sciences; TERRAPUB. both the east and west are thick sequences of ignimbrites originating from caldera in the TVZ. The Axial Main Ranges of the North Island to the east of the CVR and TVZ are made up of Mesozoic greywacke (Fig. 1) which also outcrops in isolated pockets along the western margin of the CVR but is not exposed within the CVR itself. The majority of faults through the region follow the main tectonic trend of the North Island with a concentration of faults, the Taupo Fault Belt, occurring in the centre of the TVZ.

Most of the early geophysical studies of the CVR and TVZ were associated with the development of its geothermal resources. Many of the studies concerned with the TVZ have been reviewed by Bibby et al. (1995) and only a brief overview of these is given here. The shallow structure of the TVZ has been very well defined electrically from compilations of Schlumberger direct current (dc) resistivity soundings. These clearly delineate the geothermal fields as areas of low $(<10 \Omega \mathrm{m})$ resistivity compared to a background resistivity of 100's of $\Omega \mathrm{m}$ (Bibby, 1988; Bibby et al., 1995). Bipole-dipole resistivity surveys (e.g. Risk et al., 1993, 1994; Bibby et al., 1998) and early magnetotelluric (MT) data (e.g. Ingham, 1990, 1991, 1992) indicate that outside the geothermal fields the resistivity decreases to about $10 \Omega \mathrm{m}$ at $1-2 \mathrm{~km}$ depth before rising again below about $5 \mathrm{~km}$ in depth. Bibby et al. (1995) have attributed the shallow low resistivity as being the result of a combination of elevated temperatures and alteration.

There is little geophysical control, however, on the basement structure of either the CVR or the TVZ. The depth and nature of the basement is well determined only along the eastern margin of the CVR/TVZ where the boundary 


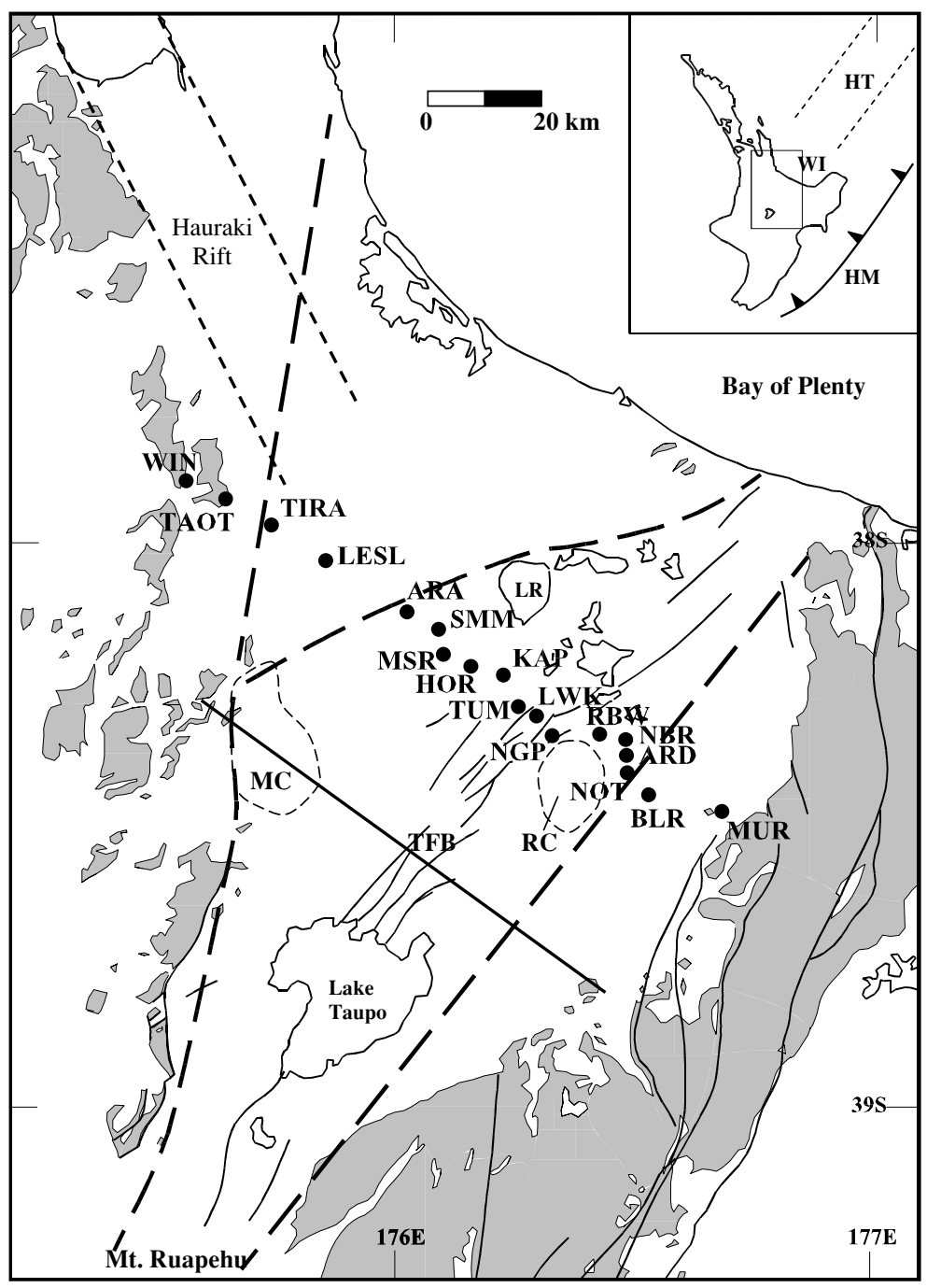

Fig. 1. Inset: North Island of New Zealand showing the study area, the Hikurangi Margin (HM), Havre Trough (HT) and the location of White Island (WI). Main map: the boundaries of the Central Volcanic Region and the Taupo Volcanic Zone, and the locations of MT sites. The thin dashed lines outline the Mangakino (MC) and Reporoa (RC) Calderas. TFB: Taupo Fault Belt, LR: Lake Rotorua. The solid line shows the location of the MT transect reported by Ogawa et al. (1999). Grey areas represent exposure of basement greywacke.

is marked by steep gravity gradients and drill holes have found greywacke at depth (Bibby et al., 1995 and references therein). In contrast, the western boundary of the CVR is not marked by a significant gravity gradient except in the south where it is coincident with the boundary of the TVZ (Hatherton, 1974).

Seismic techniques have generally proved problematic within the TVZ because of reverberations within the shallow volcaniclastics (Bannister and Melhuish, 1997). Those results that have been obtained (e.g. Robinson et al., 1981; Stern and Davey, 1985) suggest a laterally uniform velocity structure with a sharp increase in velocity beneath about $2 \mathrm{~km}$ depth. Due to the absence of greywacke and the occurrence of volcanics in drill holes away from the eastern margin of the TVZ/CVR, there is no general agreement as to the nature of this underlying high velocity layer. Because of the geological heterogeneity Bibby et al. (1995) suggest that the high velocities relate to a physical rather than lithological cause. The results of larger scale seismic refraction experiments across the North Island have been interpreted by Stern and Davey (1987) in terms of the broader crustal structure of the region. Their suggested cartoon of structure across the central North Island gives a crustal thickness of about $15 \mathrm{~km}$ within the CVR compared to a thickness of 25 $\mathrm{km}$ to the west. Stern and Davey (1987) also suggest the existence of an anomalous mantle beneath the CVR and the possibility of partial melt at relatively shallow depths. More recently Bannister et al. (2004) have used non-linear inversion of receiver functions to derive the variation in shear wave velocity across the TVZ. The results of this identify a region of low velocity beneath the TVZ with its upper surface at approximately $10 \mathrm{~km}$ depth.

Shallow seismicity occurs throughout the TVZ (Bryan et al., 1999) but is not uniformly distributed. Much of the seismicity appears to be correlated with the active part of the Taupo Fault Belt (TFB), while there is also marked seismicity associated with one or two of the geothermal fields. Both the western part of the TVZ and the Taupo-Reporoa Depression, along the eastern margin of the TVZ immediately to the north-east of Lake Taupo, are markedly aseismic. Across the whole of the TVZ Bryan et al. (1999) note that the base of the seismogenic zone appears to be at about 

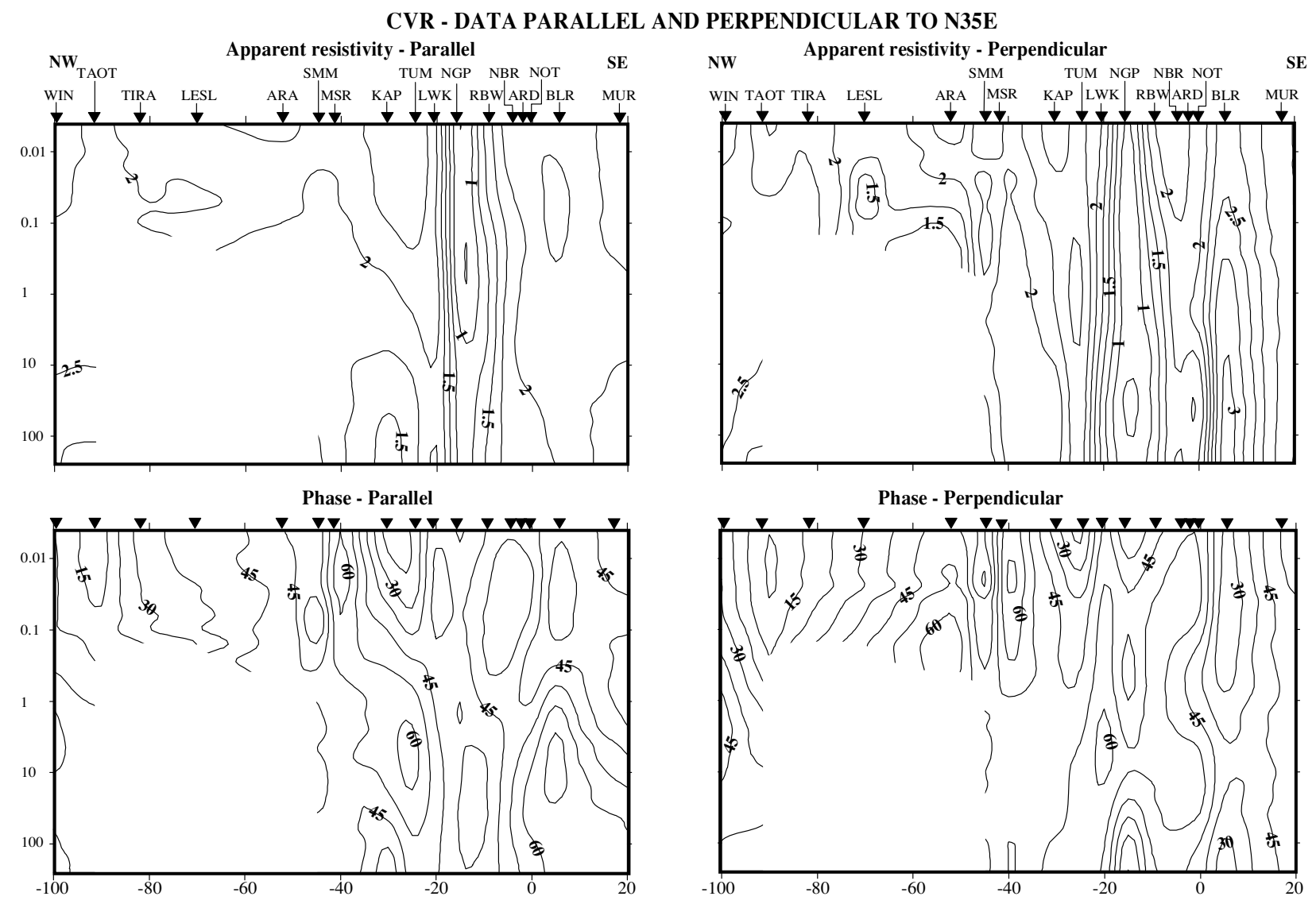

Fig. 2. Pseudosections, in orientations parallel and perpendicular to $\mathrm{N} 35^{\circ} \mathrm{E}$, of the $\log _{10}$ (apparent resistivity) and of the phase data. Apparent resistivities are in $\Omega \mathrm{m}$, and phases in ${ }^{\circ}$.

$6 \mathrm{~km}$ depth and they relate this to the transitions from brittle to ductile behaviour and from convective to conductive heat flow regimes. As the inferred depth at which low shear wave velocities occur is below this, Bannister et al. (2004) interpreted the low velocity as an indication of partial melt in the mid-crust.

Its occurrence on-land and within continental lithosphere, and the location of the CVR close to the southern termination of the west to south-west subduction associated with the Hikurangi Margin, makes the CVR a somewhat unique setting to study the tectonic processes and structure associated with the on-going development of a backarc basin. Therefore, to gain a better understanding of the tectonics of the CVR and the TVZ, and to relate these to the observed volcanism, the region is under intensive study using a variety of geophysical techniques including seismic (e.g. Bannister et al., 2004; Hoffman and Savage, 2002; Reyners et al., 2003; Stratford et al., 2002; Stratford and Stern, 2004), gravity (e.g. Horgan et al., 2002, 2003), GPS and electromagnetic. The latter part of this study involves collection of MT data across the CVR and TVZ along several lines. A transect of the TVZ just to the north of Lake Taupo has previously been reported by Ogawa et al. (1999), and is being extended further to the west. Discussed in this paper are the results from a parallel transect of MT sites some $50 \mathrm{~km}$ to the north-east crossing the CVR and TVZ just to the south of Lake Rotorua.

\section{Magnetotelluric Data}

Magnetotelluric data were collected at 18 sites on a transect of approximately $125 \mathrm{~km}$ length (Fig. 1). The transect extends from the greywacke Axial Main Ranges, at its south-eastern end, to just west of the western boundary of the CVR where isolated greywacke outcrops occur. In the south-east the transect is approximately perpendicular to the strike of the eastern boundary of the CVR/TVZ. At its north-western end it cuts obliquely across both the western boundaries of both the TVZ (as defined by Wilson et al., 1995) and the CVR. The transect is closely parallel to that which Bannister et al. (2004) used in their analysis of receiver functions to derive the variation in shear wave velocity across the TVZ.

At each measurement site the horizontal north and east components of the time varying magnetic and electric fields were measured, using the Victoria University MT system, in four overlapping frequency bands covering, in total, the nominal frequency range 500-0.005 Hz. Remote referencing (Gamble et al., 1979) was not available, but data were processed using robust analysis techniques, including coherency weighting of estimates, to give estimates of the MT impedance tensor as a function of frequency. As robust processing does not remove bias due to noise in the local magnetic field, both upward and downward biased estimates of the impedance tensor were calculated. Comparison of these indicated that there was little if any bias in the estimates of the impedance tensor and that data quality at most sites was 
good across the major part of the frequency range although some scatter in the data occurs at frequencies higher than $100 \mathrm{~Hz}$. However, in the north-western part of the transect at sites ARA, LESL and TIRA cultural noise arising mainly from electric fences seriously contaminated the data at frequencies lower than $10 \mathrm{~Hz}$. At one site, HOR, in the centre of the transect, data were unusable due to the effects of a near-by power transmission line. In addition to the MT measurements, direct current $(\mathrm{dc})$ resistivity soundings (out to a maximum current electrode spacing of between 150 and $200 \mathrm{~m}$ ) were also made at the majority of sites for use in subsequent control of static-shift (McLoughlin et al., 2002).

Pseudosections of apparent resistivity and phase as a function of period are shown in Fig. 2. The results are presented in a co-ordinate system that has been rotated so that its axes are parallel and perpendicular to the gross strike of the eastern margin of the $\mathrm{TVZ}\left(\mathrm{N} 35^{\circ} \mathrm{E}\right)$. The most striking feature of the apparent resistivity pseudosections shown in Fig. 2 is the sharp lateral variation that occurs beneath the eastern part of the TVZ between sites TUM and NBR. To a certain degree this is the result of low apparent resistivity values at site NGP which relate to the proximity of this site to the surface manifestations of the Waiotapu geothermal field. Nevertheless, despite higher apparent resistivity values to the east and west of this site, the occurrence of enhanced phase values at longer periods of between 1 and 100 s suggest the existence of low electrical resistivity at greater depth. A further rise in apparent resistivity and a lowering of phase values at the south-eastern end of the transect reflect the presence of basement greywacke at shallow depth. The absence of data at periods longer than $0.1 \mathrm{~s}$ inhibits inferences about structure beneath the western part of the CVR. At the north-west end of the transect, on the western margin of the CVR, sites TAOT and WIN are marked by strong lateral gradients in phase, and relatively uniform apparent resistivity.

\section{Dimensionality and Strike}

When the electrical resistivity structure to which MT data respond is 2-dimensional, solutions of Maxwell's equations split into TE and TM modes associated with electric fields respectively parallel and perpendicular to the strike of the electrical structure. In the present case it is tempting to assume that the well-defined eastern margin of the CVR/TVZ might impose 2-dimensionality on the recorded MT data. However, the difference in orientation between the assumed western boundaries of the TVZ and the CVR; geological heterogeneity within the TVZ; and possibly, on a larger scale, the presence of the land/sea boundary associated with the Bay of Plenty coastline, may mean that in reality the electrical structure along the transect is in fact more complex.

Many techniques have been developed for determining the dimensionality of the electrical conductivity structure to which the impedance tensor is sensitive at a given location. These range from simple rotation of the impedance tensor to determine its principal axes, to more sophisticated "decomposition" techniques discussed, for example, by Bahr (1988, 1991), Groom and Bailey (1989), Groom et al. (1993), Chave and Smith (1994), Smith (1995), Lilley (1998a, b) and McNeice and Jones (2001). Such techniques are often used to derive the most appropriate 2-dimensional form for data that are influenced by galvanic distortion or 3-dimensional effects.

Recently, Caldwell et al. (2004) have introduced the concept of the magnetotelluric phase tensor as a means of recognising the dimensionality of data. The approach taken by Caldwell et al. (2004) builds on earlier work by Bibby (1986) on the dc (direct current) apparent resistivity tensor. In this representation the phase tensor at a magnetotelluric site is defined as

$$
\Phi=X^{-1} Y
$$

where $X$ and $Y$ are the real and imaginary parts, respectively, of the measured impedance tensor. It is shown by Caldwell et al. that $\Phi$ is unaffected by distortion of the regional impedance tensor and that the dimensionality of the MT response can be assessed from three quantities: the ellipticity

$$
\lambda=\frac{\phi_{\max }-\phi_{\min }}{\phi_{\max }+\phi_{\min }}
$$

where, $\phi_{\max }$ and $\phi_{\min }$ are the magnitudes of the principal axes of the phase tensor;

$$
\beta=\frac{1}{2} \tan ^{-1}\left(\frac{\phi_{12}-\phi_{21}}{\phi_{11}+\phi_{22}}\right)
$$

the skew angle of the phase tensor; and

$$
\alpha=\frac{1}{2} \tan ^{-1}\left(\frac{\phi_{12}+\phi_{21}}{\phi_{11}-\phi_{22}}\right)
$$

which expresses the dependence of the tensor on the measurement coordinate system. $\phi_{11}, \phi_{12}, \phi_{21}$ and $\phi_{22}$ are the elements of the phase tensor in the measurement coordinate system. If $\lambda \approx 0$ and $\beta \approx 0$ the conductivity structure may be regarded as 1 -dimensional. If $\lambda \neq 0$ then the conductivity structure is not 1 -dimensional but if both $\beta \approx 0$ and the angle $\alpha-\beta$ does not vary with the period, the structure is 2 -dimensional. In this circumstance either $\alpha-\beta$ or the direction perpendicular to it indicates the strike orientation of the structure. Where either $\beta \neq 0$ or $\beta \approx 0$ but $\alpha-\beta$ varies with period the data are 3-dimensional. A visual indication of how measured data respond to electrical structure on a variety of different length and depth scales is obtained by plotting the phase tensor at each site as an ellipse (Caldwell et al., 2004). The variation in the size, shape and orientation of the ellipses both in space and with period gives a picture both of the dimensionality of the data and of the strike of the electrical structures which are dominant in different period ranges. In particular the principal axes of the ellipse indicate the direction of the regional conductivity gradient. For example, in a region where the electrical structure is 2dimensional, the ellipses will be oriented either parallel or perpendicular to the strike of the structure.

Maps of phase tensor ellipses are shown in Fig. 3 for six periods of variation. The variation with period of the ellipticity $\lambda$, the skew angle $\beta$, and the strike orientation $\alpha-\beta$ are shown for four representative sites in Fig. 4. In most cases at shorter periods than those shown in Fig. 3 the phase tensor ellipses are largely near circular, indicating 

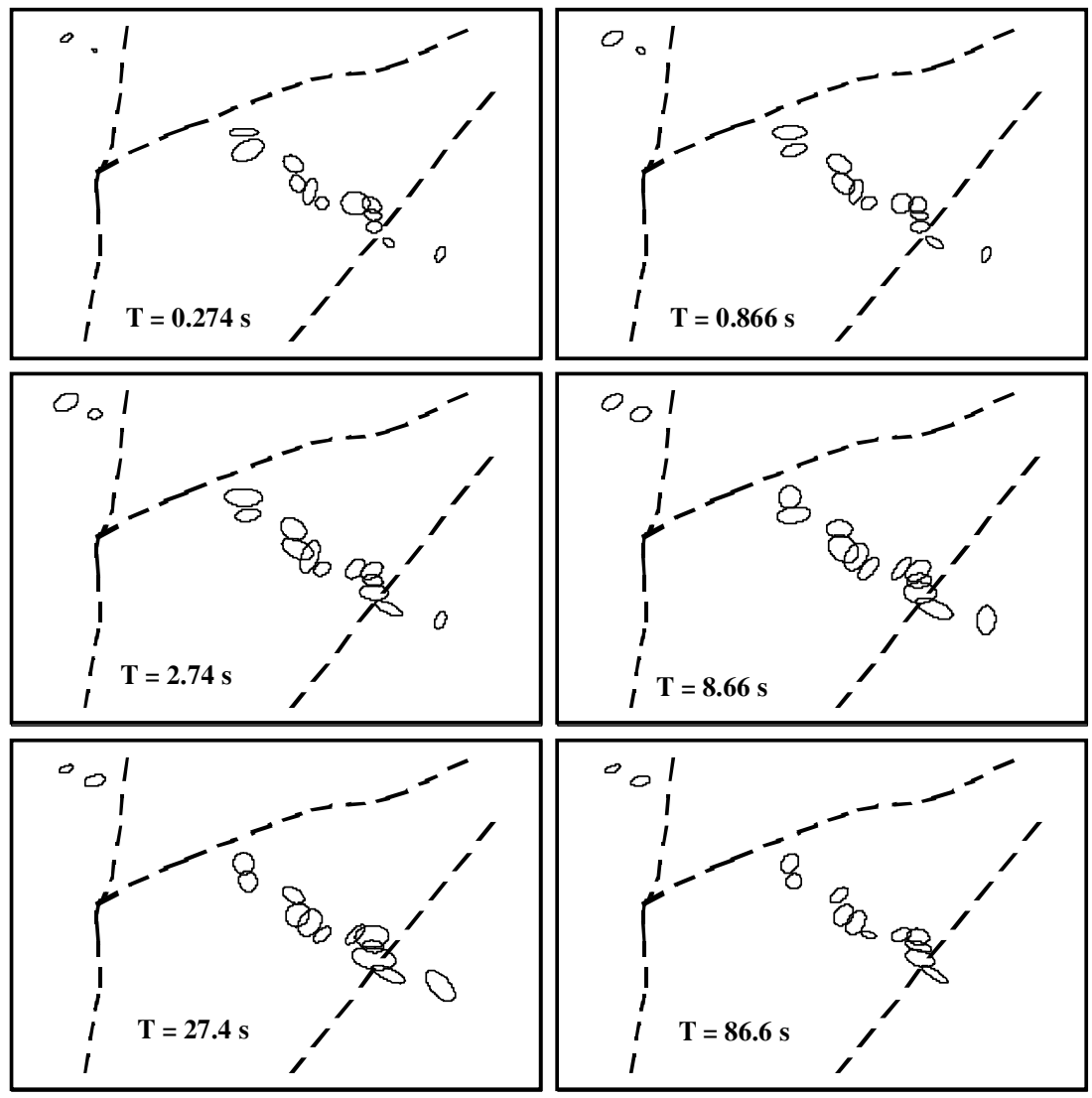

Fig. 3. Phase tensor ellipses for 6 periods of variation. As discussed in the text, the orientation of principal axes of the ellipses indicate the direction of the regional conductivity gradient.

that shallow electrical structure at each site is approximately 1-dimensional. For periods between 0.1 and $3 \mathrm{~s}$ at sites between KAP and MUR the phase tensor ellipses align either approximately parallel or perpendicular to the strike of the eastern boundary of the TVZ. In this period range, as is shown by the plots of $\lambda, \beta$ and $\alpha-\beta$ for BLR, NBR and NGP in Fig. 4, the electrical structure may be considered as 2-dimensional with a strike orientation roughly consistent with that of the eastern boundary of the TVZ. At periods greater than $3 \mathrm{~s}$, however, although the ellipses for sites between KAP and RBW retain roughly the same orientations as at shorter periods, closer to the boundary of the TVZ there are rotations of the major axis of the ellipse (Fig. 3). This is particularly noticeable at NBR, and can be seen in the variation with period of $\alpha-\beta$ in Fig. 4 , where the major axis of the ellipse rotates from $\mathrm{N} 45^{\circ} \mathrm{E}$ at $\sim 3 \mathrm{~s}$ period to a near east-west orientation at $30 \mathrm{~s}$ period. At the same time the value of $\beta$ approaches the limits of the acceptable range for 2-dimensionality (taken here as $-5^{\circ}<\beta<+5^{\circ}$ ). At even longer periods ellipses at NGP (Fig. 4) and RBW, further from the boundary, also start to exhibit the same rotation.

The apparent 3-dimensional behaviour of the phase ellipses in this region may possibly be related to the fact that along the transect the exact location of the eastern edge of the TVZ is not as clearly defined as it is to the south. Bibby et al. (1998) modelled bipole-dipole dc resistivity data along a number of transects of the eastern boundary of the TVZ and found that in the south the topographic scarp of the Kaingaroa Fault coincided with the contrast in resistivity across the boundary. This was not the case further to the north. Just to the south of the present MT transect Bibby et al. (1998), following Risk et al. (1993), found that the topographic feature lies to the west of the resistivity contrast and inferred that the extension of the Kaingaroa scarp in this region has a strike more closely aligned south-north and marks the edge of the Reporoa Caldera rather than the actual boundary of the TVZ. The boundary of the TVZ itself is masked by deposits of the Kaingaroa Ignimbrite, sourced from the Reporoa Caldera, which are less resistive than, and overlie, the older Rangitaiki Ignimbrite which occurs to the east of the TVZ further to the south. The existence of two sub-parallel resistivity boundaries associated with the edges of the TVZ and the Reporoa Caldera provide a possible explanation for the rise in the value of $\beta$ at periods above $\sim 10$ $\mathrm{s}$ at sites lying between the two boundaries. At short periods the ellipses align either parallel or perpendicular to the assumed boundary of the TVZ but at periods above about 10 $s$ the dominant structure appears to be the Reporoa Caldera and the ellipses start to rotate into an orientation which is perpendicular to its local edge. Evidence of a degree of 3dimensionality within the TVZ close to its eastern boundary was also identified by Caldwell et al. (2004) in their application of the phase tensor to the data reported by Ogawa $e t$ al. (1999).

At sites within or adjacent to the Taupo Fault Belt (KAP, TUM and LWK), although the phase tensor ellipses generally align parallel or perpendicular to the eastern boundary 

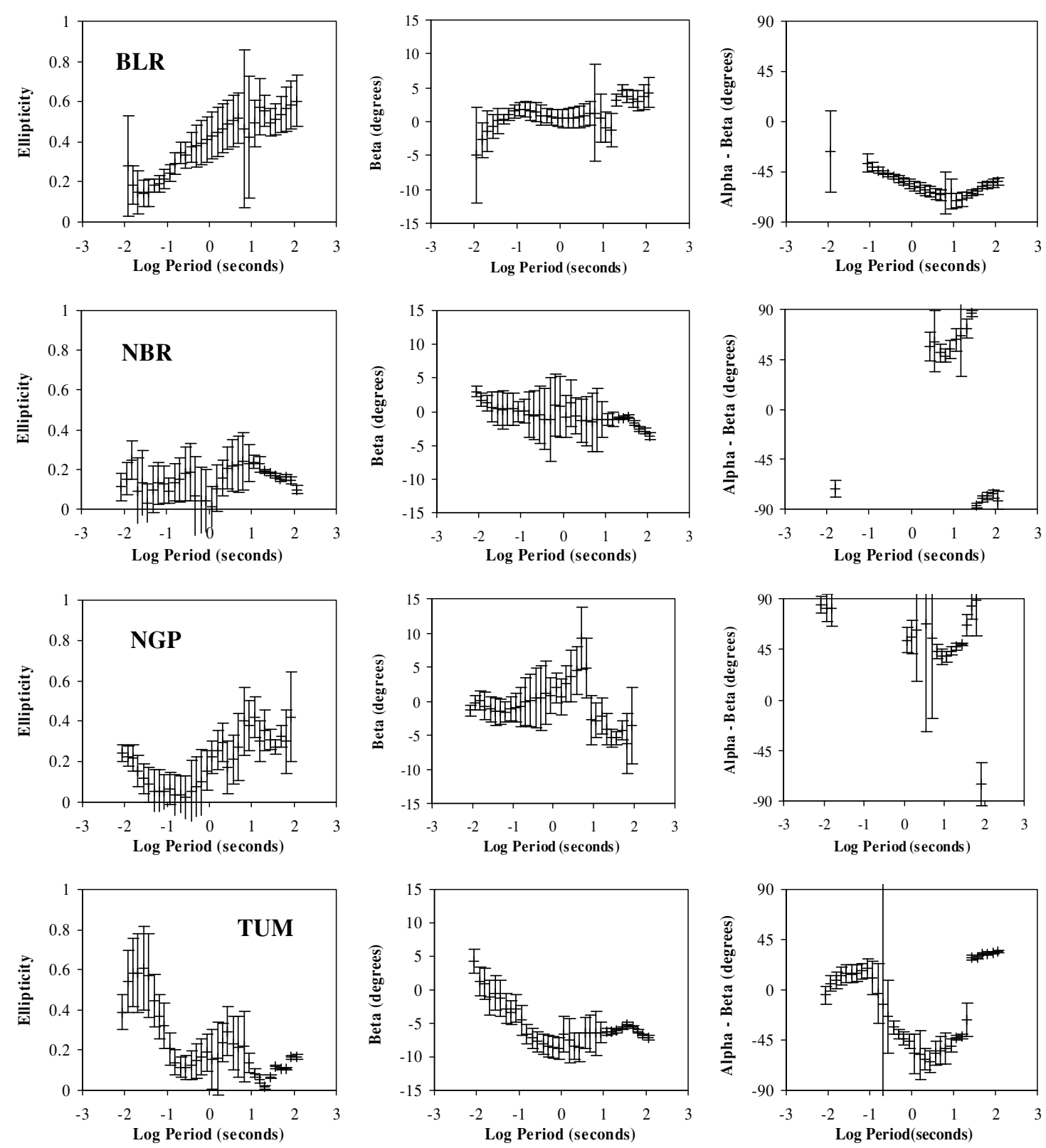

Fig. 4. Phase tensor ellipticity, skewness and strike orientation for representative sites across the CVR. Azimuth angles are not shown for periods at which the ellipticity and $\beta$ indicate that the data are 1-dimensional.

of the TVZ (Fig. 3), the behaviour of the skew and strike angles give strong indications of 3-dimensionality in the conductivity structure. The variation in these parameters at TUM (Fig. 4) is typical, with a large change in $\beta$ occurring between periods of 0.01 and $0.3 \mathrm{~s}$ and resulting in relatively stable longer period values of $\beta$ of $\sim-7^{\circ}$. In terms of the derived strike angle this appears as a rotation in $\alpha-\beta$ from approximately $0^{\circ}$ to a north-west to south-east orientation. The same kind of behaviour in $\beta$ is also observed further to the north-west at SMM and MSR where data are 1 -dimensional for periods less than about $0.1 \mathrm{~s}$ and where $\lambda$ is also small at long periods but $\alpha-\beta$ is very poorly defined.

At the two sites at the north-western end of the transect, TAOT and WIN, $\beta \approx 0$ and the phase ellipses show a very consistent orientation of approximately $\mathrm{N}^{\circ} \mathrm{E}$. The structure is therefore clearly indicated to be 2-dimensional. However, this orientation does not correspond to one which is either parallel or perpendicular to that of the adjacent western boundary of the CVR. A potential structure to which the data at TAOT and WIN may be sensitive is provided by the Hauraki Rift (Fig. 1). The Hauraki Rift (or Depression) extends at least $150 \mathrm{~km}$ with a north-west to south-east trend as a broad valley with a width of approximately $25 \mathrm{~km}$. Its structure has been described by Hochstein and Nixon (1979) based on the modelling of gravity and seismic profiles. They modelled the rift as being bounded by normal faults and divided into two parts of 5-10 km width by a median ridge. Within each of the two downfaulted blocks the sedimentary thickness was determined to be between $2.5-3.5 \mathrm{~km}$, with up to $2 \mathrm{~km}$ of Tertiary sediments at the base of the this sequence. At its south-eastern end the Hauraki Rift ceases to be a distinct geographical feature close to the western boundary of the CVR (Fig. 1). The rift is believed to be currently tectonically active as is 


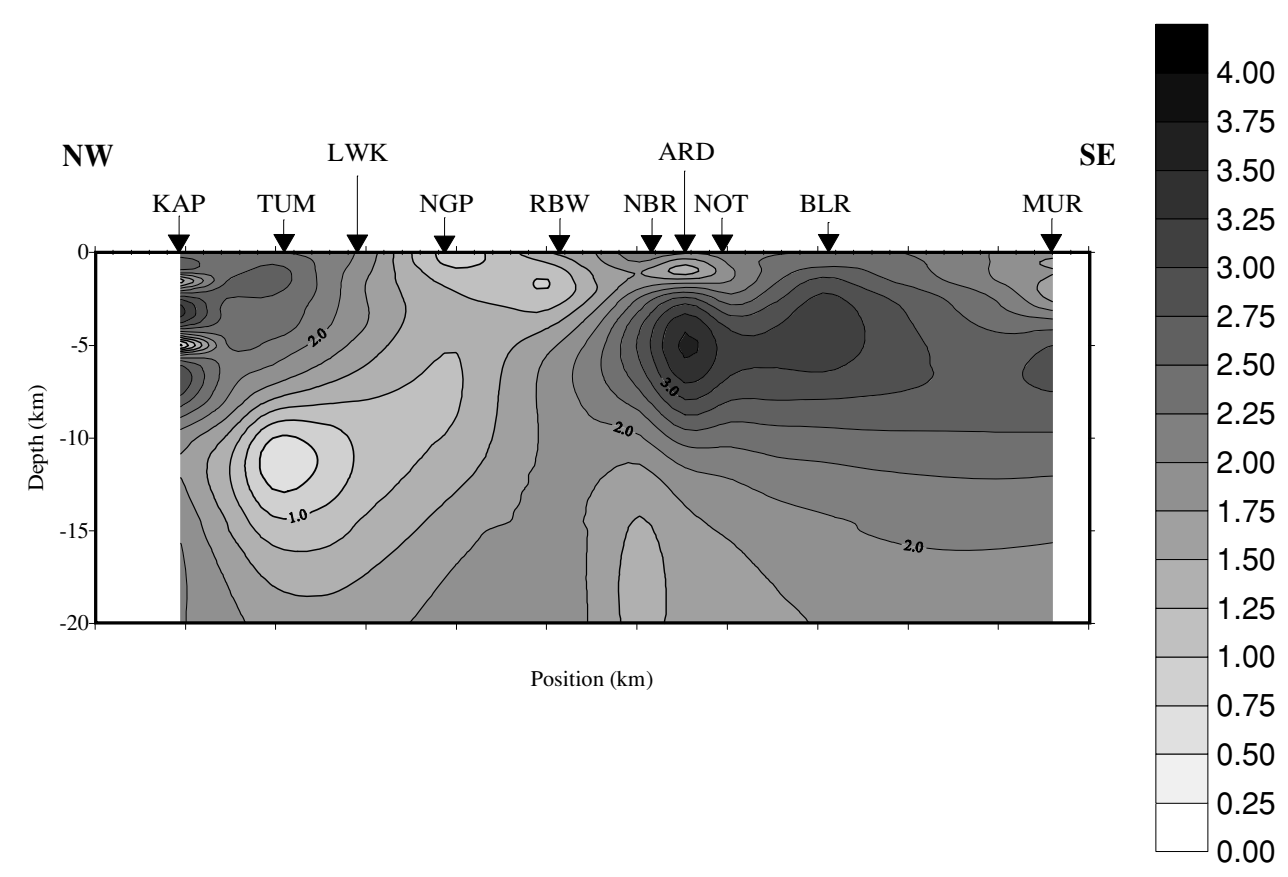

Fig. 5. 2-dimensional electrical resistivity model derived from joint inversion of the TE and TM magnetotelluric responses. Contours are of log 10 (resistivity). Resistivities are in $\Omega \mathrm{m}$.

witnessed by the presence of hot springs at several locations along its length. Given the low electrical resistivity $(\sim 10$ $\Omega \mathrm{m})$ normally associated with Tertiary sediments (e.g. Ingham et al., 2001) the Hauraki Rift is likely to provide a significant electrical contrast with the surrounding Quaternary and volcanic sequences and may therefore give rise to the 2-dimensional response seen at WIN and TAOT. Nevertheless, without further MT data both across the western flank of the CVR and across the Hauraki Rift, it is impossible to draw more specific conclusions about the electrical structure beneath this part of the transect.

In summary, maps of the manner in which the phase tensor ellipses vary with period and analysis of their characteristic parameters suggests that up to periods of 10-30 s data from the south-eastern part of the transect are largely 1 or 2-dimensional in nature although it is clear that there is possibly some greater complexity to structure both immediately adjacent to the assumed eastern margin of the TVZ, and within the Taupo Fault Belt. Detailed inspection of the preferred orientations of the phase tensor ellipses in the period ranges where the data are 2-dimensional rather than 1-dimensional shows that the best estimate of the strike direction to which these data respond is $\mathrm{N} 45^{\circ} \mathrm{E}$. This is the same orientation which was derived by Ogawa et al. (1999) using the Groom and Bailey (1989) distortion technique, but in this case is derived using the properties of the phase tensor without any prior assumption concerning dimensionality. At the north-west end of the transect, however, the structure is clearly much more complicated with definite indications of 3-dimensionality.

\section{2-dimensional Numerical Modelling of the Taupo Volcanic Zone}

In an attempt to gain some indication of the electrical conductivity structure associated with that part of the tran- sect for which 2-dimensionality is broadly indicated, 2dimensional inversion of the apparent resistivity and phase data at the 10 sites from KAP to MUR has been carried out using the Rapid Relaxation Inversion (RRI) code of Smith and Booker (1991). This part of the transect spans the central part of the TVZ from the greywacke outcrops of the Main Ranges across the Taupo Fault Belt. The results obtained should therefore have some comparability to those presented by Ogawa et al. (1999) and give some indication of the continuity or non-continuity of electrical features along the length of the TVZ.

At most of the sites the data used in the inversion have been restricted to those periods less than $30 \mathrm{~s}$. Data at periods where there is a significant rotation of the calculated value of $\alpha-\beta$ have therefore been excluded. At sites within the Taupo Fault Belt (KAP, TUM, LWK), where rotation of the ellipses occurs at shorter periods, a cut-off period of 10 $s$ has been used. The same is also true at BLR where there is a jump in $\beta$ at this period. The data to be inverted have been obtained from the original measured data by rotating the impedance tensor into a co-ordinate system aligned with the identified strike orientation. Prior to inversion the results of dc resistivity soundings at each site have been used to provide a correction for static-shift of the MT apparent resistivity data. This has been accomplished using the technique described in detail by McLoughlin et al. (2002). In this technique the results of 1-dimensional inversion of the dc resistivity data are used to generate the expected MT response at high frequency $(>100 \mathrm{~Hz})$. This is then matched to the observed MT data calculated from the determinant impedance (Ranganayaki, 1984) and allows an assessment of the true value of MT apparent resistivity at high frequency. At all sites the degree of static-shift in the data was found to be very small $(<0.2$ of a decade in apparent resistivity). 

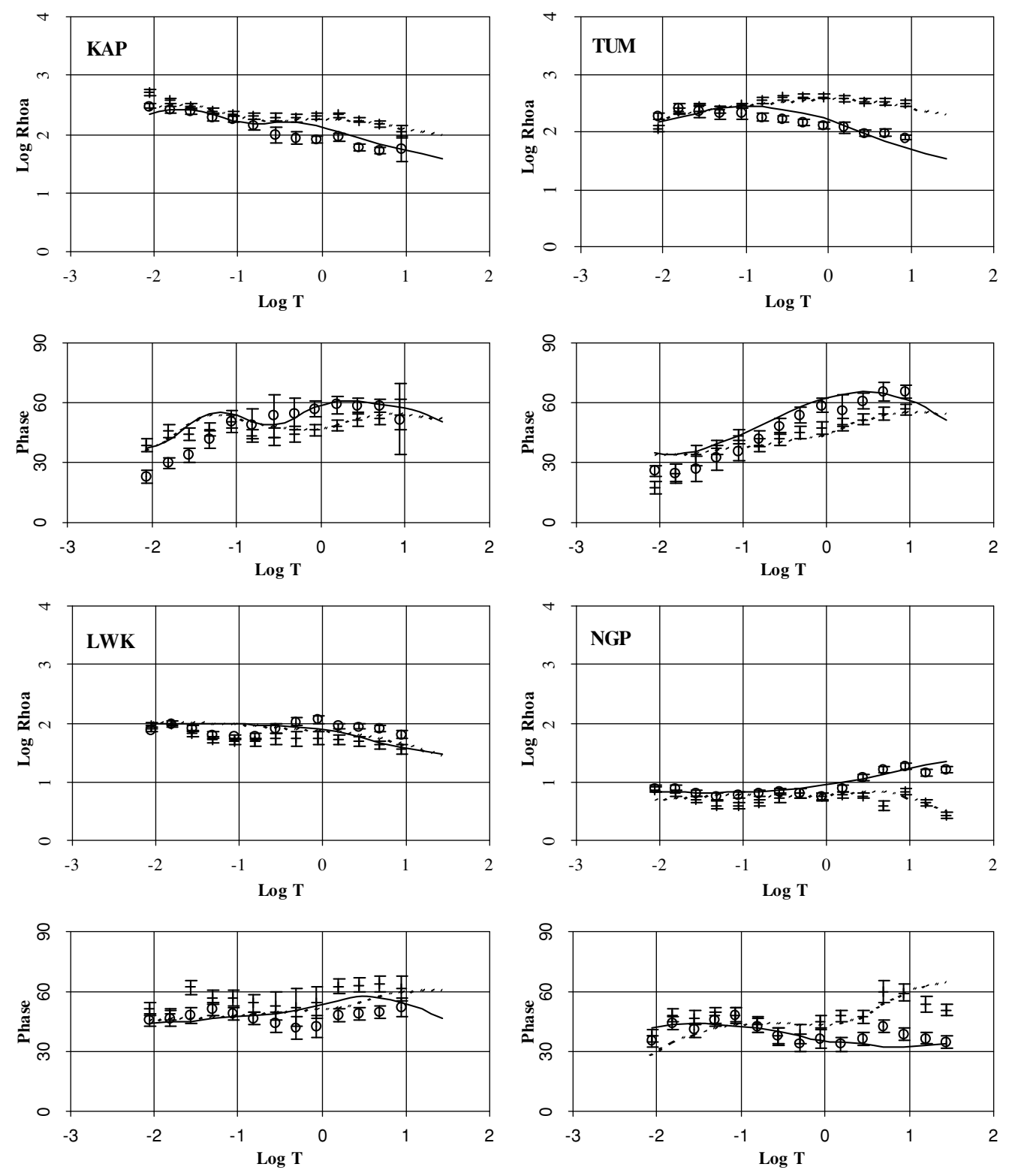

Fig. 6. Fit of the model responses to the measured MT data. Circles represent the TE mode data, crosses represent the TM mode data. Solid and dashed lines represent the TE and TM model responses respectively. Apparent resistivities are in $\Omega \mathrm{m}$, phases in ${ }^{\circ}$, and period $(T)$ in $\mathrm{s}$.

A variety of 2-dimensional inversions have been performed (i) using different minimum error levels for the measured data; (ii) seeking to fit the data to different levels of rms error; and (iii) performing both joint and individual inversions of the TE and TM mode data. In all cases the derived electrical resistivity structure exhibits the same major features. These are illustrated in Fig. 5 which shows the result of a joint inversion of the TE and TM mode data using a minimum error level of $10 \%$ in $\log _{10}\left(\rho_{a}\right)$ and with target rms values, varying from site to site, which were obtained by initially inverting the data with target rms values of 1.0 at all sites. The overall achieved rms error of this model was 1.66 , with a lower rms misfit to the phase data than to the apparent resistivity data. The visual fit of this model to the observed TE and TM data at the individual sites is shown in Fig. 6.

The main features of the model may be summarised as follows. (1) The existence of a large region of low resis- tivity $(\sim 10-100 \Omega \mathrm{m})$ below about $10 \mathrm{~km}$ depth between sites KAP and NGP. (2) A very sharp rise in resistivity between about 2 and $10 \mathrm{~km}$ depth beneath NBR and NOT, with somewhat lower resistivity values at shallower depths. (3) A low surface resistivity $(\sim 10 \Omega \mathrm{m})$ between NGP and RBW. The fact that separate inversions of the TE and TM data also show these basic features suggests that they are robust and required by both polarisations of the MT data. The fit to the data is generally good at all sites (Fig. 6). Minor exceptions to this include over-estimation of the long period TM apparent resistivity at NOT and an inability, while fitting the general shape of the curves, to fit the undulations in the apparent resistivity curves at TUM and LWK. Use of a more restrictive target rms value improves the fit at these sites at the expense of a somewhat rougher resistivity structure in the near surface. Oscillations in the model structure beneath the most north-western site KAP are poorly constrained. 

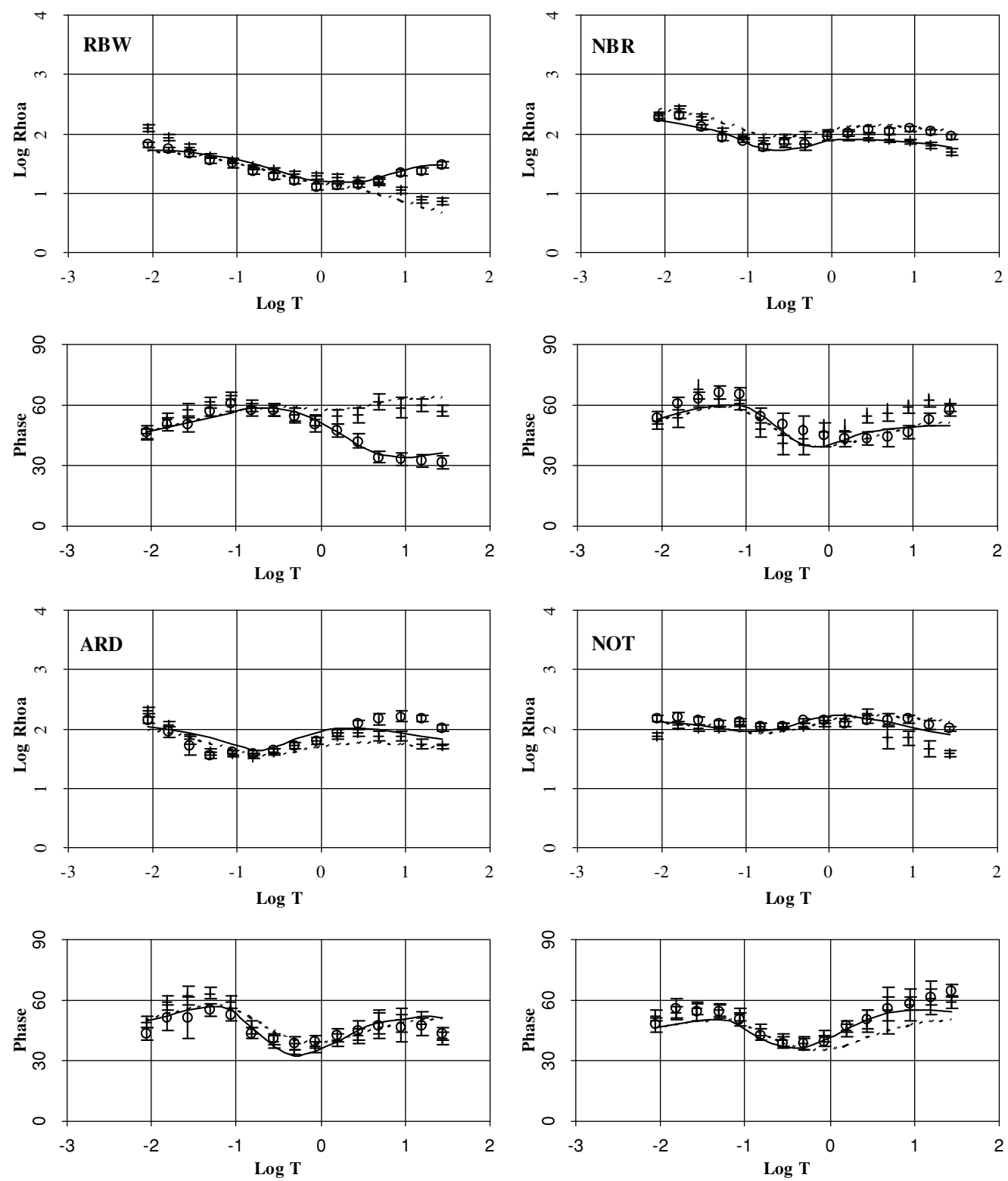

Fig. 6. (continued).

To assess the sensitivity of the data to the presence of the main features of the derived structure, 2-dimensional forward modelling has also been carried out. In particular the sensitivity of the data to the deep low resistivity region beneath KAP, TUM, LWK and NGP has been tested by observing the effect that changes to the low resistivity region have on the fit of 2-dimensional model responses to the data at these sites. Changing an initial model based on Fig. 5 by (i) replacing the central core of resistivity $10 \Omega \mathrm{m}$ with 30 $\Omega \mathrm{m}$, and (ii) replacing both the 10 and $30 \Omega \mathrm{m}$ regions by a higher resistivity, progressively degrades the fit to the observed data in the period range from 1-10 s. The largest effect is on the phase data in both TE and TM modes at sites KAP and TUM. This is illustrated in Fig. 7 which shows the manner in which both TE and TM phase values at periods above $1 \mathrm{~s}$ are reduced as the resistivity of the initially low resistivity region is increased. The decrease in phase values at $\sim 1 \mathrm{~s}$ period results in a significant underfitting of the observed phase data. For example the rms misfit in the
TM phase data from TUM, in the period range 1 to $10 \mathrm{~s}$, increases from 1.538 to 3.216 when the resistivity of the deep conductor is changed from 10 to $30 \Omega \mathrm{m}$. Increasing the resistivity to $100 \Omega \mathrm{m}$ further increases the rms misfit. It can be concluded that the deep low resistivity region, with a resistivity of $\sim 10 \Omega \mathrm{m}$ is a required feature of the model. Modelling also shows that the top of this low resistivity region must be at least as shallow as $8 \mathrm{~km}$ but may be slightly shallower. The depth to which the low resistivity extends is not constrained by the data. Similar analyses show that the surface low resistivity between NGP and RBW and the location of the sharp rise in resistivity at the eastern margin of the TVZ are both features that are well constrained by the data.

A comparison of the derived 2-dimensional electrical resistivity structure shown in Fig. 5, with that obtained by Ogawa et al. (1999) from MT sites on a transect $50 \mathrm{~km}$ to the south-west, is shown in Fig. 8. The two models exhibit significant similarities which suggests that over this 

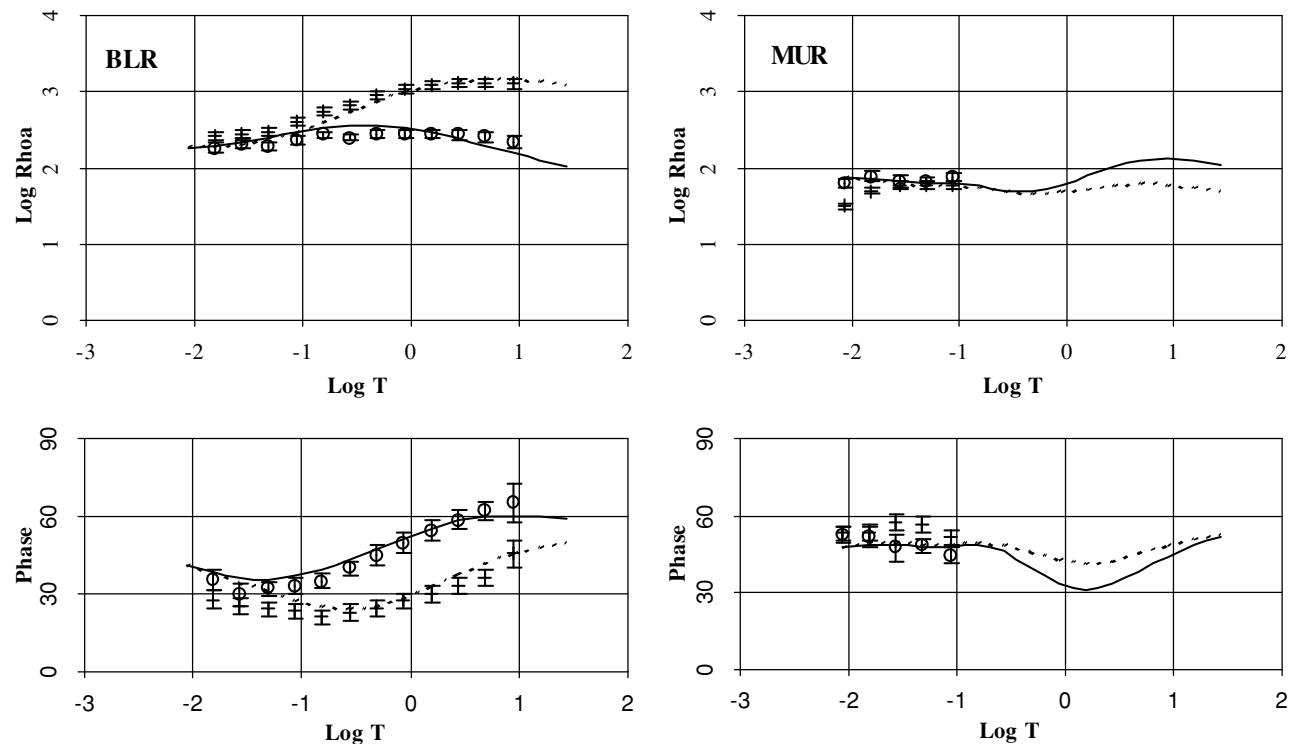

Fig. 6. (continued).
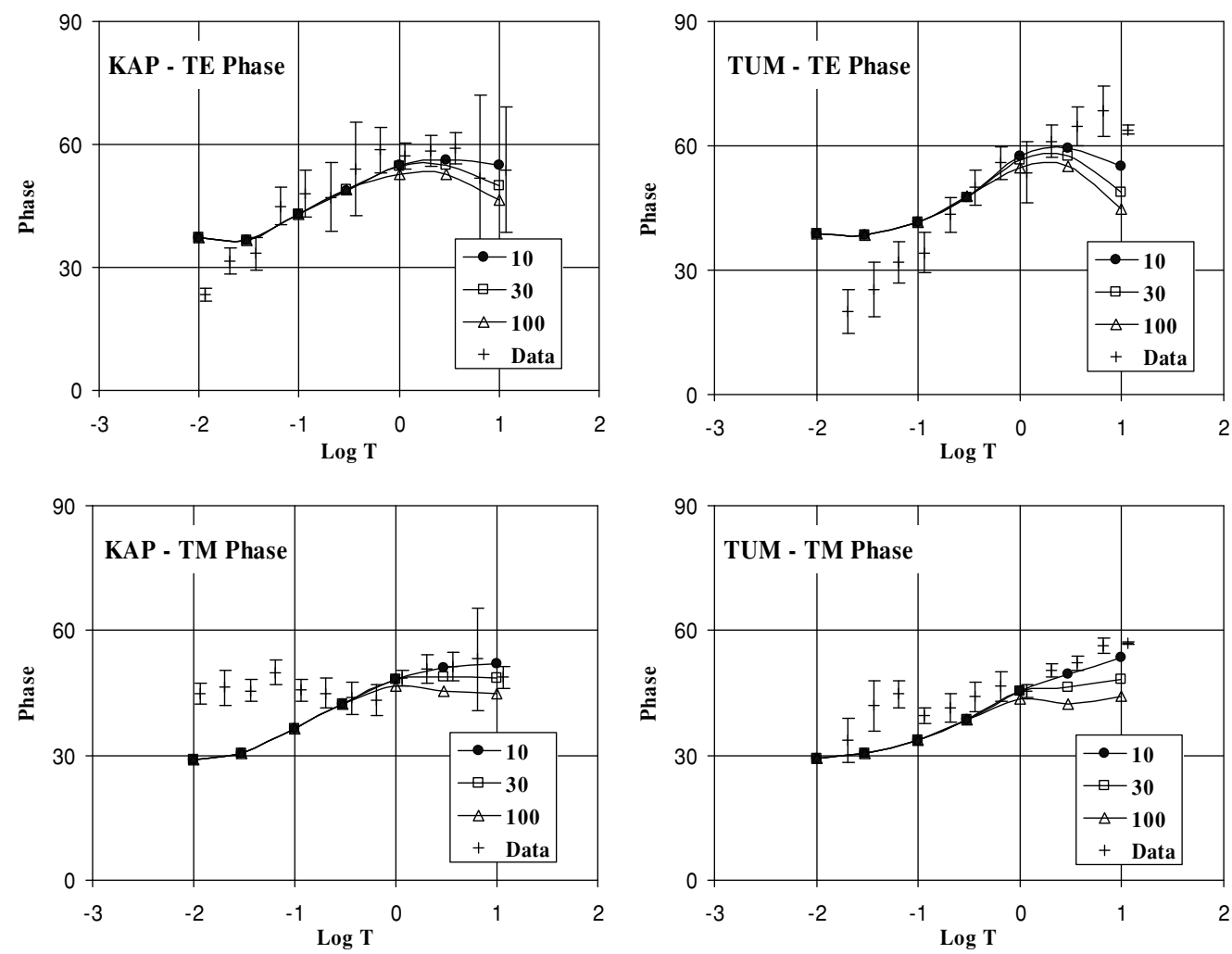

Fig. 7. TE and TM phase at KAP and TUM calculated for 2-dimensional forward models based on the resistivity structure shown in Fig. 5. 10: forward model corresponding to the structure shown in Fig. 5; 30: forward model in which the $10 \Omega \mathrm{m}$ core of the deep low resistivity region is changed to 30 $\Omega \mathrm{m}$; 100: forward model in which the entire deep low resistivity region is replaced by $100 \Omega \mathrm{m}$.

part of its length, notwithstanding the possibility of some 3-dimensionality within the Taupo Fault Belt, the TVZ has a largely 2-dimensional resistivity structure. The low resistivity (labelled 1 in Fig. 8) below $10 \mathrm{~km}$ depth coincides with the location of an electrically conductive feature, similar in both depth extent and location in the model derived by Ogawa et al. As the model presented in Fig. 5 does not fully resolve the base of this feature and its relationship to any deeper conductor, such as that identified by Ogawa et al. (labelled 1a in Fig. 8) is speculative. The possible origin of this apparently extensive region of low resistivity is discussed below. The large resistivity contrast at the southeastern end of the transect is also similar in location and magnitude to that observed by Ogawa et al. (1999) across the eastern margin of the TVZ/CVR. The high resistivity values that occur at $\sim 2 \mathrm{~km}$ depth to the east of NBR reflect the presence of basement greywacke (feature 2 in Fig. 8) and are similar to values that occur in the Ogawa et al. 


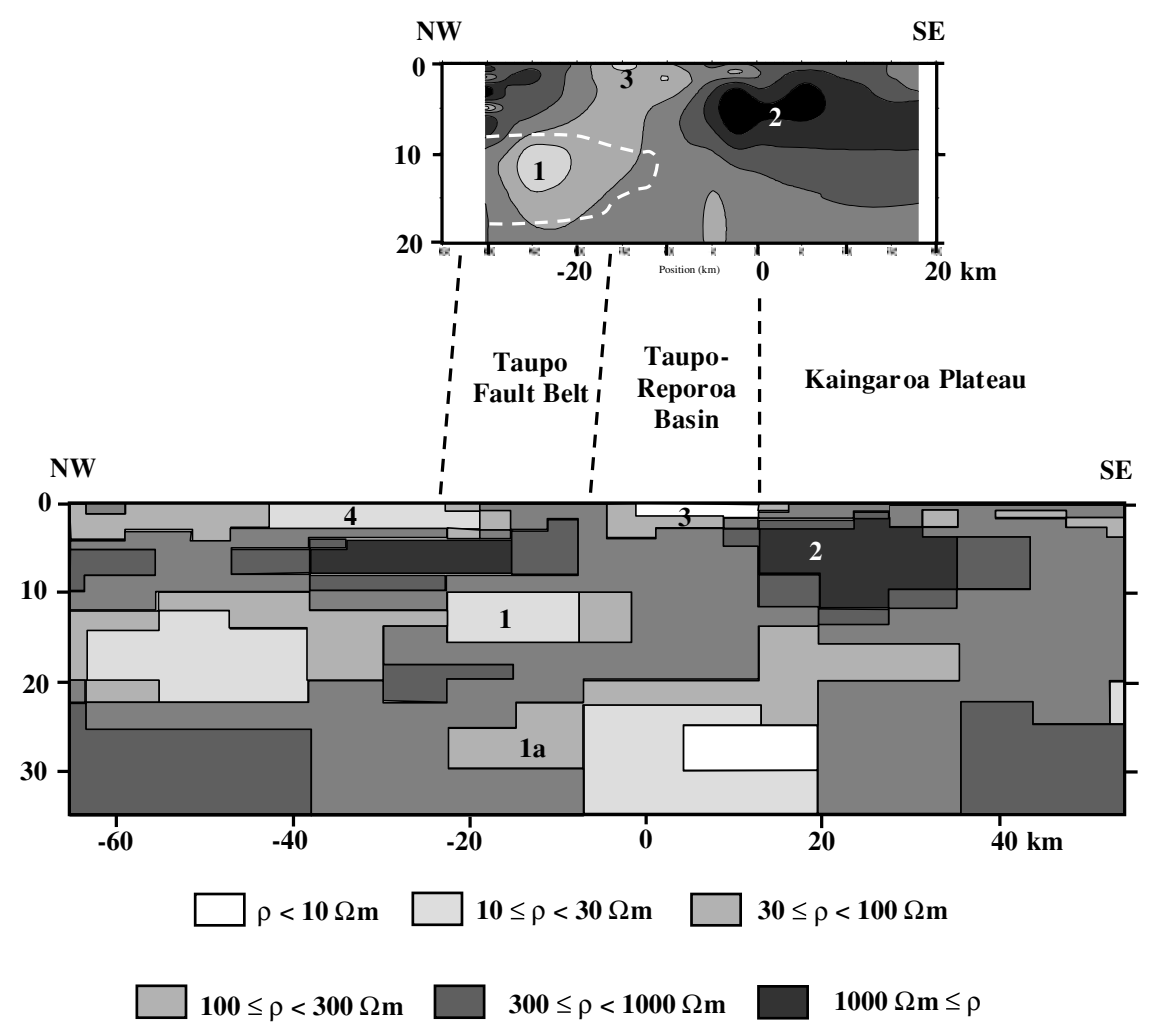

Fig. 8. Comparison of the 2-dimensional resistivity model shown in Fig. 7 with that derived by Ogawa et al. (1999). The dashed line represents the extent of the low shear wave velocity identified by Bannister et al. (2004).

model. This high resistivity on the Kaingaroa Plateau is also in agreement with the results of Bibby et al. (1998) who interpreted dc resistivity data in terms of an increase in the resistivity of the greywacke basement with depth. The MT data do not resolve the actual shallow structure of the eastern boundary of the TVZ/CVR in detail. However, the general shape shown in Figs. 5 and 8 is in broad agreement with the series of down-stepping normal faults derived from gravity and seismic data by Stagpoole (1994). The slightly lower resistivity in the upper $2 \mathrm{~km}$ between NBR and NOT is also consistent with the existence of sub-parallel resistivity contrasts associated with the masking of the eastern boundary of the TVZ by the Kaingaroa Ignimbrite.

The 2-dimensional model presented by Ogawa et al. (1999) also shows a near surface region of high conductivity along the eastern margin of the TVZ (3 in Fig. 8). This was related by the authors to the alteration of igneous rocks (Bibby et al., 1998) within the sequence of collapsed calderas (structurally referred to as the TaupoReporoa Basin) that exist along this margin. The near surface conductor (beneath NGP and RBW) identified in the present study occupies a similar location relative to the eastern margin of the TVZ. In this case, however, at this location the MT transect passes along the northern boundary of the Waiotapu geothermal field. As a result the near surface low resistivity region is likely to be associated partly with alteration of the surface volcanic rocks and to partly reflect the low resistivity associated with the geothermal field itself. The apparent connection, in Fig. 5, of this surface low resistivity with the deeper conductor to the north-west is poorly resolved due to the reduced skin-depth in the over- lying conductive material. A region of low resistivity at the surface was also reported by Ogawa et al. (1999) in the western part of their transect (4 in Fig. 8) and was also interpreted to be associated with the presence of a caldera (the Mangakino caldera).

\section{Implications of Low Resistivity beneath the Taupo Fault Belt}

The existence of low resistivity at a depth of $\sim 10 \mathrm{~km}$ centred beneath the Taupo Fault Belt has significant implications for the origin of the observed volcanism and geothermal features within the TVZ. The observed electrically conductive regime at depth is consistent with many of the previous observations concerning the nature of heat transfer within the TVZ, and also with other, recent, geophysical measurements.

The most pertinent results are those of Bannister et al. (2004) who presented the shear wave velocity structure along a cross-section across the TVZ following basically the same line as the MT transect discussed here. Bannister et al. (2004) found low shear wave velocity beneath the TVZ at depths below about $8-10 \mathrm{~km}$ with a lateral extent (shown by the dashed line in Fig. 8) which is in good agreement with the observed deep conductive region beneath the Taupo Fault Belt. They inferred the low velocity to be the result of partial melt, citing the depth of the upper surface of the low velocity region to be close to the minimum depth of magma chambers that could be expected on petrological arguments (Wilson et al., 1984). Geochemical evidence (Giggenbach, 1995) also indicates that partial melting of rocks occurs at depth within the TVZ. On the basis of early 
evidence from seismic travel-times, Robinson et al. (1981) have previously calculated the maximum possible amount of melt to be $\sim 4 \%$. If the resistivity of melt is assumed to be $1 \Omega m$ (e.g. Müller and Haak, 2004), the Hashin-Shtrikman limits for the conductivity of a connected mixture (Hashin and Shtrikman, 1962) imply that a melt fraction of $\sim 5 \%$ is sufficient to provide a bulk resistivity of $\sim 10-30 \Omega \mathrm{m}$. The MT results are compatible with such an interpretation.

Bibby et al. (1995) have argued that the convective systems associated with the geothermal fields within the TVZ may penetrate to depths of around $8 \mathrm{~km}$. Within the convective systems downflow occurs in regions outside the geothermal fields. Within the rising geothermal plumes the increase in temperature with depth is controlled by the convective process and leads to a temperature at the base of the convective regime of about $350^{\circ} \mathrm{C}$. If $350^{\circ} \mathrm{C}$ is representative of the temperature at $8 \mathrm{~km}$ depth throughout the TVZ, and, assuming that the base of the crust (and the thermal lithosphere at $1300^{\circ} \mathrm{C}$ ) lies at $\sim 15 \mathrm{~km}$ depth (Stern and Davey, 1987; Stratford et al., 2002; Stratford and Stern, 2004), this implies that beneath the convective regime a conductive temperature gradient exists of about $130^{\circ} \mathrm{C} / \mathrm{km}$. Bibby et al. (1995) suggest that this is insufficient to supply the observed average surface heat flow of $\sim 700 \mathrm{~mW} / \mathrm{m}^{2}$ and that to supply the necessary heat there must therefore be repeated episodes of volcanic intrusion into the crust to at least $12 \mathrm{~km}$ depth and probably shallower. Some evidence supporting this comes from analysis of marine magnetic data from the Bay of Plenty where Horgan et al. (2002, 2003) suggest that a thermally enhanced lithosphere exists beneath the CVR and that the Curie point occurs at only $\sim 9$ $\mathrm{km}$ depth. Horgan et al. also report gravity data that indicate that the crust has been thinned by repeated rifting and that $\sim 10 \mathrm{~km}$ thickness of lower crustal material has been replaced by igneous intrusions. A coherent explanation for the origin of the low resistivity region would therefore be that it results from igneous intrusion into the crust beneath the Taupo Fault Belt.

In conjunction with the results of Ogawa et al. (1999), the results of this study provide a picture of the deep electrical structure of the Taupo Volcanic Zone. Although more detailed analysis of the effects of 3-dimensionality of data from within the Taupo Fault Belt is necessary, the identification of low resistivity beneath about $10 \mathrm{~km}$ depth appears to give a clear indication of the existence of partial melt beneath this central part of the TVZ. Nevertheless such an interpretation leaves the problem of the lateral offset between the low resistivity region and the location of the major geothermal fields along the eastern margin of the TVZ. However this is not inconsistent with seismic observations as, for example, Bryan et al. (1999) have argued that the uniformity of the base of the seismogenic zone across the TVZ means that it is not necessary for volcanic intrusions to lie beneath the regions of convective upflow.

In contrast details of the deep electrical structure associated with the western part of the Central Volcanic Region remain unclear. It seems likely that observed 2dimensionality at sites in this area may arise from the strong electrical contrast associated with Hauraki Rift.
Acknowledgments. This work was carried out under the auspices of New Zealand Foundation for Research Science and Technology Contract No. VIC807. Reviews from Phil Wannamaker and Makoto Uyeshima greatly improved the manuscript.

\section{References}

Bahr, K., Interpretation of the magnetotelluric impedance tensor: Regional induction and local telluric distortion, J. Geophys., 62, 119-127, 1988.

Bahr, K., Geological noise in magnetotelluric data: A classification of distortion types, Phys. Earth Planet. Int., 66, 24-38, 1991.

Bannister, S. C. and A. Melhuish, Seismic scattering and reverberation, Kaingaroa Plateau, Taupo Volcanic Zone, New Zealand, N. Z. Jl. Geol. Geophys., 40, 375-381, 1997.

Bannister, S., C. J. Bryan, and H. M. Bibby, Shear wave velocity variation across the Taupo Volcanic Zone, New Zealand, from receiver function inversion, Geophys. J. Int., 159, 291-310, 2004.

Bibby, H. M., Analysis of multi-source bipole-dipole resistivity surveys using the apparent resistivity tensor, Geophysics, 51, 972-983, 1986.

Bibby, H. M., Electrical resistivity mapping in the central volcanic region of New Zealand, N. Z. Jl. Geol. Geophys., 31, 259-274, 1988.

Bibby, H. M., T. G. Caldwell, F. J. Davey, and T. H. Webb, Geophysical evidence on the structure of the Taupo Volcanic Zone and its hydrothermal circulation, J. Volcanol. Geotherm. Res., 68, 29-58, 1995.

Bibby, H. M., T. G. Caldwell, and G. F. Risk, Electrical resistivity image of the upper crust within the Taupo Volcanic Zone, New Zealand, $J$. Geophys. Res., 103, 9665-9680, 1998.

Bryan, C. J., S. Sherburn, H. M. Bibby, S. C. Bannister, and A. W. Hurst, Shallow seismicity of the central Taupo Volcanic Zone, New Zealand: its distribution and nature, N. Z. Jl. Geol. Geophys., 42, 533-542, 1999.

Caldwell, T. G., H. M. Bibby, and C. Brown, The magnetotelluric phase tensor, Geophys. J. Int., 158, 457-469, 2004.

Chave, A. D. and J. T. Smith, On electric and magnetic galvanic distortion tensor decompositions, J. Geophys. Res., 99, 4669-4682, 1994.

Cole, J. W., Structural control and origin of volcanism in the Taupo Volcanic Zone, New Zealand, Bulletin of Volcanology, 52, 445-459, 1990.

Gamble, T. D., W. M. Goubou, and J. Clarke, Magnetotellurics with a remote reference, Geophysics, 44, 53-68, 1979.

Giggenbach, W. F., Variations in the chemical and isotopic composition of fluids discharged in the Taupo Volcanic Zone, New Zealand, J. Volcanol. Geotherm. Res., 68, 89-116, 1995.

Groom, R. W. and R. C. Bailey, Decomposition of the magnetotelluric impedance tensor in the presence of local three-dimensional galvanic distortion, J. Geophys. Res., 94, 1913-1925, 1989.

Groom, R. W., R. D. Kurtz, A. G. Jones, and D. E. Boerner, A quantitative methodology to extract regional magnetotelluric impedances and determine the dimension of the conductivity structure, Geophys. J. Int., $\mathbf{1 1 5}$, 1095-1118, 1993.

Hashin, Z. and A. Shtrikman, A variational approach to the theory of effective magnetic permeability of multiphase materials, J. Appl. Phys., 33, 3125-3131, 1962.

Hatherton, T., Basement surface west of Lake Taupo, Geophysics Division, DSIR, report 90, 1974.

Hochstein, M. P. and I. M. Nixon, Geophysical study of the Hauraki Depression, North Island, New Zealand, N. Z. Jl. Geol. Geophys., 22, 1-19, 1979.

Hochstein, M. P., I. E. M. Smith, K. Regenauer-Lieb, and S. Ehara, Geochemistry and heat transfer processes in Quaternary rhyolitic systems of the Taupo Volcanic Zone, New Zealand, Tectonophysics, 223, 213-235, 1993.

Hoffman, S. D. and M. K. Savage, Seismic anisotropy of the crust and upper mantle on the western edge of the Central Volcanic Region, North Island, New Zealand, Eos. Trans. AGU, 83(22), West. Pac. Geophys. Meet. Suppl., Abstract SE32A-04, 2002.

Horgan, H., G. Lamarche, and T. Stern, Constraining extensional tectonic structures in a back-arc environment using geopotential and multi-channel seismic data - the offshore Bay of Plenty, New Zealand, Eos. Trans. AGU, 83(22), West. Pac. Geophys. Meet. Suppl., Abstract SE22C-02, 2002.

Horgan, H., G. Lamarche, and T. Stern, Constraints on the thermal and crustal structure of the offshore Central Volcanic Region, New Zealand, New Zealand Geophysical Society Symposium, Wellington, New Zealand, 1-2 September, 2003.

Ingham, M., Electrical conductivity structure of the eastern margin of the Central Volcanic Region, Proc. 12th NZ Geothermal Workshop, 77-81, 1990. 
Ingham, M., Electrical conductivity structure of the Broadlands-Ohaaki geothermal field, New Zealand, Phys. Earth Planet. Int., 66, 62-75, 1991.

Ingham, M., Numerical modelling of magnetotelluric soundings from the central Volcanic Region, Proc. 13th NZ Geothermal Workshop, 15-19, 1992.

Ingham, M., K. Whaler, and D. McKnight, Magnetotelluric sounding of the Hikurangi Margin, New Zealand, Geophys. J. Int., 144, 343-355, 2001.

Lilley, F. E. M., Magnetotelluric tensor decomposition: 1. Theory for a basic procedure, Geophysics, 63, 1885-1897, 1998a.

Lilley, F. E. M., Magnetotelluric tensor decomposition: 2. Examples of a basic procedure, Geophysics, 63, 1898-1907, 1998b.

McLoughlin, C., M. Ingham, C. Whaler, and D. McKnight, A magnetotelluric transect of the Wairarapa region, New Zealand, N. Z. Jl. Geol. Geophys., 45, 257-269, 2002.

McNeice, G. W. and A. G. Jones, Multisite, multifrequency tensor decomposition of magnetotelluric data, Geophysics, 66, 158-173, 2001.

Müller, A. and V. Haak, 3-D modeling of the deep electrical conductivity of Merapi volcano (Central Java): integrating magnetotellurics, induction vectors and the effect of steep topography, J. Volcan. Geotherm. Res., Germany, 138, 205-222, 2004.

Ogawa, Y., H. M. Bibby, T. G. Caldwell, S. Takakura, N. Matsushima, S. L. Bennie, T. Tosha, Y. Nishi, Wide-band magnetotelluric measurements across the Taupo volcanic zone : preliminary results, Geophys. Res. Lett., 26, 3673-3676, 1999.

Ranganayaki, R. P., The interpretive analysis of magnetotelluric data, Geophysics, 49, 1730-1748, 1984.

Reyners, M., D. Eberhart-Phillips, and G. Stuart, Seismic tomography in the central North Island-a progress report from CNIPSE. New Zealand Geophysical Society Symposium, Wellington, New Zealand, 1-2 September, 2003.

Risk, G. F., H. M. Bibby, and T. G. Caldwell, Dc resistivity mapping with the multiple-source bipole-dipole method in the Central Volcanic Region, New Zealand, J. Geomag. Geoelectr., 45, 897-916, 1993.

Risk, G. F., T. G. Caldwell, and H. M. Bibby, Deep resistivity surveys in the Waiotapu-Waikite-Reporoa region, New Zealand, Geothermics, 23, 423-443, 1994.

Robinson, R. E., E. G. C. Smith, and J. H. Latter, Seismic studies of the crust under the hydrothermal areas of the Taupo Volcanic Zone, New
Zealand, J. Volcanol. Geotherm. Res., 9, 253-267, 1981.

Smith, J. T., Understanding telluric distortion matrices, Geophys. J. Int., 122, 219-226, 1995.

Smith, J. T. and J. R. Booker, Rapid inversion of two- and threedimensional magnetotelluric data, J. Geophys. Res., 96, 1168-1171, 1991.

Stagpoole, V. M., Interpretation of refraction seismic and gravity data across the eastern margin of the Taupo Volcanic Zone, New Zealand, Geothermics, 23, 501-510, 1994.

Stern, T. A., A back-arc basin formed within continental lithosphere: the central Volcanic Region of New Zealand, Tectonophysics, 112, 385409, 1985.

Stern, T. A., Asymmetric back-arc spreading, heat-flux and structure associated with the Central Volcanic Region of New Zealand, Earth Planet. Sci. Lett., 85, 265-276, 1987.

Stern, T. A. and F. J. Davey, Crustal structure studies with the central North Island: The Central Volcanic Region, Report 207, Geophysics Division, DSIR, Wellington, 47 pp, 1985.

Stern, T. A. and F. J. Davey, A seismic investigation of the crustal and upper mantle structure within the Central Volcanic Region of New Zealand, $N$. Z. Jl. Geol. Geophys., 30, 217-231, 1987.

Stratford, W. R. and T. A. Stern, Strong seismic reflections and melts in the mantle of a continental back-arc basin, Geophys. Res. Lett., 31, doi:10.1029/2003GL019232, 2004.

Stratford, W. R., T. A. Stern, and the North Island Geophysical Transect (NIGHT) working group, Crust and upper mantle structure in continental bark-arc spreading zone: Central North Island, New Zealand, Eos. Trans. AGU, 83(22), West. Pac. Geophys. Meet. Suppl., Abstract SE32B-05, 2002.

Wilson, C. J. N., A. M. Rogan, I. E. M. Smith, D. J. Northey, I. A. Nairn, and B. F. Houghton, Caldera volcanoes of the Taupo Volcanic Zone, New Zealand, J. Geophys. Res., 89, 8463-8484, 1984.

Wilson, C. J. N., B. F. Houghton, M. D. McWilliams, S. D. Lanphere, S. D. Weaver, and R. M. Briggs, Volcanic and structural evolution of Taupo Volcanic Zone, New Zealand: a review, J. Volcanol. Geotherm. Res., 68, 1-28, 1995.

M. Ingham (e-mail: Malcolm.Ingham@vuw.ac.nz) 